\title{
Oral health attitudes/behavior and gingival self-care level of Korean dental hygiene students
}

\author{
Kang-Ju Kim ${ }^{\S}$, Takashi Komabayashi ${ }^{\dagger}$, Sang-Eun Moon ${ }^{\S}$, Kyong-Mi Goo ${ }^{\ddagger}$, \\ Mitsugi Okada* and Makoto Kawamura" \\ ${ }^{\S}$ Department of Oral Microbiology and Wonkwang Dental Research Institute, Wonkwang University, Korea \\ $\dagger$ Institute of Biomaterials and Bioengineering, Tokyo Medical and Dental University, Tokyo 113-8510 \\ †Department of Occupational Health, Graduate School, Chonbuk National University, Korea \\ Departments of *Pediatric Dentistry and "Preventive Dentistry, Hiroshima University School of Dentistry, \\ Hiroshima 734-8553
}

(Received 6 September 2000 and accepted 14 February 2001)

\begin{abstract}
The purpose of this study was to examine oral health attitudes/behavior and gingival self-care levels of Korean dental hygiene students $(n=271)$. A questionnaire known as HU-DBI (Korean version) was administered to each class. Higher scores of the HUDBI indicate better oral health attitudes/behavior. The student's gingival self-care level was scored as excellent $(+2), \operatorname{good}(+1)$, questionable $(0)$, poor $(-1)$, or very poor $(-2)$ according to the criteria of the Oral Rating Index (ORI) for youth. The mean score of the HUDBI was 6.40, and that of the ORI was +0.12. Most samples scored 0 or +1 . The mean HU-DBI scores of year-2 and year-3 students (7.06, and 7.61 respectively) were significantly greater than that of year-1 students (5.23) $(P<0.001)$. Twenty-three percent of the students reported a belief that they may eventually require false teeth. Half stated that they put off going to the dentist until they had toothache. Year-1 students were more likely to have this attitude compared to year-3 students. HU-DBI scores were significantly associated with ORI scores $(r=0.315 ; P<0.001)$. The differences in the HUDBI and ORI scores across the level of education were
\end{abstract}

Correspondence to Dr. Makoto Kawamura, Department of Preventive Dentistry, Hiroshima University School of Dentistry, 1-2-3, Kasumi, Minami-ku, Hiroshima, 734-8553, Japan.

Phone: +81-82-257-5651 Fax: +81-82-257-5650

E-mail address: makoto@hiroshima-u.ac.jp highly significant. (J. Oral Sci. 43, 49 - 53 , 2001)

Key words: oral health attitudes/behavior; gingival self-care level; dental hygiene students; Korea.

\section{Introduction}

In Korea, there are three types of dental personnel: dentists, dental hygienists and dental laboratory technicians. Generally, dental students' exposure to oral health education consists of only two hours of lectures, four hours of laboratory practice and one hour of practice in a primary school classroom. Thus, most dentists do not know much about oral health education (1). The duties of dental hygienists licensed by the Medical Auxiliaries Law of Korea include applying fluorides and pit and fissure sealant, providing oral prophylaxis, under the direct supervision of a dentist, and assisting in chair-side and oral health education. Dental hygienists specialize in preventive information and oral health promotion (2-5). Abraham et al. (6) indicated that, in general, dental practitioners "practiced what they preached". They concluded that the positive attitudes of dental hygienists towards the care of their own teeth and gums is important in determining the oral health conditions of their patients. In passing through the curriculum, the dental hygiene student should be able to set a personal example in oral health.

Recently Kawamura et al. (7) reported that dental 
hygiene school curricula might exert an influence on oral health attitudes/behavior of Japanese dental hygiene students. Although much published research has focused on how to motivate patients to follow a prescribed, effective gingival health care program throughout their lives (8), little attention has been given to when and how attitudes and behavior of dental hygiene students towards gingival health change.

The Hiroshima University-Dental Behavioral Inventory (HU-DBI), developed by Kawamura (9), has been shown to be useful for understanding patients' perceptions and oral health behavior in Japan. The HU-DBI comprises 20 items dealing mainly with toothbrushing behavior. All items of the HU-DBI have a dichotomous response format (agree/disagree). Summation of appropriate agree/disagree responses gives a quantitative estimate of oral health attitudes/behavior. The maximum possible score is 12 (Cronbach's alpha $=0.76(9)$ ). Higher scores indicate better oral health attitudes/behavior. The main purpose of this study was to examine the oral health attitudes/behavior and gingival self-care level of Korean dental hygiene students, using the HU-DBI Korean version and the Oral Rating Index (ORI) for youth (10). The data collected addresses two aims: 1) when and how the attitude and behavior of dental hygiene students to oral health change (comparison of year-1, year-2 and year-3 dental hygiene students), 2) whether the relationship between the Korean version of the HU-DBI and the ORI is similar to that found for the Japanese version.

\section{Materials and Methods}

A preliminary Korean version was obtained by translating the HU-DBI from the English version (11). It was translated by two bilingual Korean experts experienced in survey research using questionnaires. Back-translation was used during this translation process. Minor corrections were made, after which the resulting version was used in the present study.

In June 1998, the director of a school for dental hygienists was contacted to administer the questionnaire to their classes in the middle of the academic year (March to December). Students were asked to remain after class if they were willing to complete a survey form about their dental health attitudes/behavior and gingival self-care level. Participation was voluntary and no information about academic records was gathered. Two hundred and seventy-one of the originally enrolled students (316) formed the basis of the present analysis. Six of the dental hygiene students were male.

The students' gingival self-care level was scored as excellent $(+2)$, good $(+1)$, questionable $(0)$, poor $(-1)$, or very poor (-2) according to the criteria of the ORI for youth (11). The assessment of the ORI score is weighted by mainly gingival condition, followed by calculus accumulation and plaque accumulation. The examination was performed by a single examiner (G. K-m.) and the time taken was about ten seconds per student.

Descriptive statistics, including group means and their standard deviations are presented, unless otherwise stated. The chi-squared test was used to examine differences in the distribution of selected characteristics of the HU-DBI among three levels of education. Mann-Whitney $U$ tests for unpaired data were used to analyze differences between group means. The relationship between HU-DBI and ORI scores was analyzed by means of Spearman's rank correlation coefficient. Statistical significance was based on probability values of less than 0.05 . Data were analyzed using the SPSS Professional Statistics Release 6.xJ (SPSS, Inc., Chicago, USA).

\section{Results}

Table 1 presents the means of HU-DBI and ORI for each group. The mean score of the HU-DBI was 5.23, and that of the ORI was -0.04 on entry to the school. The mean HUDBI scores of year-3 students (7.61) and year-2 students (7.06) were significantly higher than that of year-1 students (Mann-Whitney U test; $P<0.001$ ). The mean ORI score of year-3 students $(0.36)$ was significantly higher than that of year-1 students (Mann-Whitney U test; $P<0.01$ ). The mean ORI score of year- 2 students $(0.15)$ was higher than that of year-1 students, but not to a significant extent.

Table 2 presents, by level of student education, the HUDBI statements and percentage distribution of the students who agreed with the statements. The differences were notable in four items (items 10, 14, 16 and 20) among the three groups. About $40 \%$ of the year- 1 group reported that their gums tend to bleed when they brush their teeth (item 2), whereas $26 \%$ of year- 2 students and $19 \%$ of year-3 students agreed with this statement $(P<0.05)$. More than two thirds of the year-1 group reported that they have never been taught professionally how to brush (item 10), whereas $17 \%$ of year- 2 students and $12 \%$ of year-3 students agreed with this statement $(P<0.001)$. Fewer than $5 \%$ of year- 1 students answered that they had used a dye to see how clean their teeth are (item 16), whereas the majority of year-2 and year-3 groups answered that they had done so $(P<0.001)$. Fewer than $15 \%$ of year- 1 and year-2 students said their dentist had told them that they brush very well (item 20 ), whereas $54 \%$ of the year- 3 group claimed this was so $(P<0.001)$.

However, differences among the three groups were small or not found for some items. In response to the 
question about "having noticed some white sticky deposits on their teeth" (item 4) positive replies were almost equal for all groups. More than half of each group reported that they brush each of their teeth carefully (item 9). Nearly $80 \%$ of each group said they often check their teeth in a mirror after brushing (item 12). Similarly, the differences were also small for worrying about the color of gums (item 7) and about bad breath (item 13).

Figure 1 shows the percentage of subjects distributed according to the ORI score for each level of education. Few
Table 1 Mean HU-DBI and mean ORI by level of education

\begin{tabular}{l|cccc}
\hline & Total & Year 1 & Year2 & Year 3 \\
\cline { 2 - 5 } Variable & $271(316)$ & $118(123)$ & $86(99)$ & $67(94)$ \\
\hline HU-DBI & $6.40 \pm 2.06$ & $5.23 \pm 1.76$ & $7.06 \pm 2.01 * * *$ & $7.61 \pm 1.49 * * *$ \\
ORI & $0.12 \pm 0.77$ & $-0.04 \pm 0.88$ & $0.15 \pm 0.60$ & $0.36 \pm 0.69 * *$ \\
\hline I:Mean \pm S.D. \\
Parentheses indicate the number of enrollment at Chunnam Techno College Oral Hygiene Course. \\
Significant differences of the HU-DBI and ORI between Year 1 and the other levels using Mann- \\
Whitney's U tests; $* *: P<0.01, * * *: P<0.001$. NS: Not significant.
\end{tabular}

Table 2 Questionnaire items of the HU-DBI and percentage of 'agree' response by level of education

\begin{tabular}{|c|c|c|c|c|c|}
\hline \multirow[b]{2}{*}{ Item descriptions } & \multirow[b]{2}{*}{ Total } & \multicolumn{3}{|c|}{ Year } & \multirow[b]{2}{*}{$x^{2}$ test } \\
\hline & & 1 & 2 & 3 & \\
\hline 1. I don't worry much about visiting the dentist. & 56 & 62 & 50 & 52 & NS \\
\hline 2. My gums tend to bleed when I brush my teeth. ${ }^{(D)}$ & 30 & 38 & 26 & 19 & $*$ \\
\hline 3. I worry about the color of my teeth. & 37 & 46 & 35 & 24 & * \\
\hline 4. I have noticed some white sticky deposits on my teeth. ${ }^{(A)}$ & 41 & 42 & 40 & 43 & NS \\
\hline 5. I use a child sized toothbrush. & 8 & 8 & 2 & 15 & $*$ \\
\hline 6. I think that I cannot help having false teeth when I am old. ${ }^{(D)}$ & 23 & 25 & 21 & 24 & NS \\
\hline 7. I am bothered by the color of my gums. & 8 & 11 & 5 & 7 & NS \\
\hline 8. I think my teeth are getting worse despite my daily brushing. ${ }^{(D)}$ & 22 & 27 & 21 & 15 & NS \\
\hline 9. I brush each of my teeth carefully. ${ }^{(A)}$ & 60 & 56 & 62 & 64 & NS \\
\hline 10. I have never been taught professionally how to brush. ${ }^{(D)}$ & 39 & 71 & 17 & 12 & $* * *$ \\
\hline 11. I think I can clean my teeth well without using toothpaste. ${ }^{(A)}$ & 8 & 6 & 7 & 13 & NS \\
\hline 12. I often check my teeth in a mirror after brushing. ${ }^{(A)}$ & 78 & 78 & 74 & 82 & NS \\
\hline 13. I worry about having bad breath. & 36 & 40 & 31 & 33 & NS \\
\hline 14. It is impossible to prevent gum disease with toothbrushing alone. ${ }^{(D)}$ & 46 & 57 & 35 & 39 & ** \\
\hline 15. I put off going to the dentist until I have toothache. ${ }^{(D)}$ & 50 & 56 & 47 & 45 & NS \\
\hline 16. I have used a dye to see how clean my teeth are. ${ }^{(A)}$ & 45 & 3 & 70 & 88 & *** \\
\hline 17. I use a toothbrush which has hard bristles. & 12 & 14 & 14 & 6 & NS \\
\hline 18. I don't feel I've brushed well unless I brush with strong strokes. & 34 & 35 & 40 & 24 & NS \\
\hline 19. I feel I sometimes take too much time to brush my teeth. ${ }^{(A)}$ & 19 & 14 & 20 & 25 & NS \\
\hline 20. I have had my dentist tell me that I brush very well. & 23 & 13 & 14 & 54 & $* * *$ \\
\hline
\end{tabular}

In the calculation of the HU-DBI: ${ }^{(A)}=$ One point is given for each of these agree responses. ${ }^{(\mathrm{D})}=$ One point is given for each of these disagree responses.

Significant differences among the levels of education; *: $P<0.05$, **: $P<0.01, * * *: P<0.001$, NS: Not significant. 


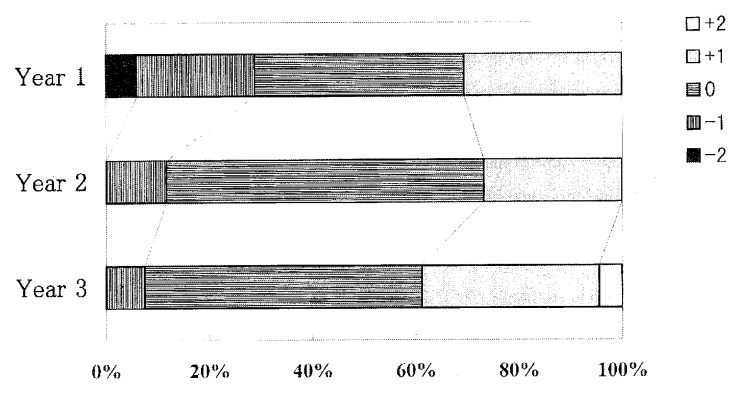

Fig. 1 Distribution of dental hygiene students according to ORI-score by level of education (gingiral self-care level: $-2=$ very poor, -1 = poor, $0=$ questionable,+1 $=$ good,$+2=$ excellent .

Table 3 Distribution of korean students By HU-DBI and ORI

\begin{tabular}{|c|c|c|c|c|c|c|}
\hline \multirow[b]{2}{*}{ HU-DBI } & \multicolumn{5}{|c|}{ ORI } & \multirow[b]{2}{*}{ Total } \\
\hline & -2 & -1 & 0 & +1 & +2 & \\
\hline $0 \sim 2$ & 1 & 4 & 2 & 2 & & 9 \\
\hline 3 & 1 & 9 & 6 & 1 & & 17 \\
\hline 4 & 3 & 7 & 8 & 6 & & 24 \\
\hline 5 & 1 & 4 & 18 & 12 & 1 & 36 \\
\hline 6 & 1 & 9 & 22 & 17 & & 49 \\
\hline 7 & & 6 & 34 & 13 & 1 & 54 \\
\hline 8 & & 2 & 22 & 13 & 1 & 38 \\
\hline 9 & & & 17 & 11 & & 28 \\
\hline $10 \sim 12$ & & 1 & 8 & 7 & & 16 \\
\hline Total & 7 & 42 & 137 & 82 & 3 & 271 \\
\hline \multicolumn{7}{|c|}{ Total : Spearman's $\mathrm{r}_{\mathrm{s}}=0.274(\mathrm{~N}=271), \quad P<0.001$} \\
\hline \multicolumn{7}{|c|}{ Year 1: Spearman's $\mathrm{r}_{\mathrm{s}}=0.252(\mathrm{~N}=118), \quad P<0.01$} \\
\hline \multicolumn{7}{|c|}{ Year 2: Spearman's $\mathrm{r}_{\mathrm{s}}=0.293(\mathrm{~N}=86), \quad P<0.01$} \\
\hline \multicolumn{7}{|c|}{ Year 3: Spearman's $r_{s}=0.160(N=67)$, N.S. } \\
\hline
\end{tabular}

students were judged as having healthy gingivae and meticulous oral hygiene $(\mathrm{ORI}=+2)$. Most of the students were scored 0 or +1 . None of year- 2 and 3 students was scored -2 , whereas $6 \%$ of year-1 students were scored 2 . Table 3 shows the distribution of the students by HUDBI and ORI. HU-DBI scores were significantly associated with ORI scores (Spearman's $\mathrm{r}_{\mathrm{s}}=0.274 ; P<0.001$ ). These relations were also found for each level of education except for year-3.

\section{Discussion}

Most ( $86 \%)$ of the enrolled students participated in the study. The course of study is three years, and students begin clinical experience in the third year of the course. The mean HU-DBI score of year-2 students was much higher than that of year-1 students, which suggested year- 2 dental hygiene students had been positively influenced to improve their oral health attitudes/behavior only one year or so after entering the school. Year-1 Korean dental students mainly learn subjects related to oral health science during Semester 2. Year-2 dental hygiene students had received a threemonth clinical practice and supervised clinical instruction in Preventive Dentistry before participating in the study. The results suggested that, as found for Japanese dental hygiene students (7), oral health attitudes/behavior of Korean dental hygiene students may have been substantially influenced by their course content and experience.

The mean score of year-1 Korean dental hygiene students was somewhat lower than that of their Japanese peers. In a cross-cultural study using the HU-DBI, Kawamura et al. (12) reported that Japanese dental students (5.57) appeared to have poorer oral health behavior than Australian ones (6.56) on entry, but that the HU-DBI score of year-6 Japanese students (9.57) was considerably higher than that of Australian final year students (7.97). There has been little effort aimed at students' self-care motivation by Semester 3 in the Korean dental hygiene school curriculum. Particularly notable is the finding that most Korean dental hygiene students upon entry into school reported not having received toothbrushing instruction and never having used a dye to test the cleanliness of their teeth. These percentages were much lower than those of their year-1 Japanese peers (40\% and $60 \%$ respectively) (7). The exposure of year- 2 dental hygiene students to concepts such as preventive dentistry, behavioral dental science and public dental health measurably affected their oral health attitudes/behavior. However, early contact with patients was not introduced until quite recently at the school. Previously, clinical training for patients had started at the beginning of year-3. Frazier (13) has stated "education is necessary but not sufficient to prevent oral diseases". Although there was no significant difference in HU-DBI between year-1 and year- 2 students, the ORI between year- 1 and year- 3 students differed significantly. Gingival self-care might have improved during this two-year period and probably reflected the greater sense of self-control and self-efficacy the students experienced through the curriculum. The school curriculum may be a fundamental factor that influences oral health attitudes/behavior, and thus the gingival selfcare of Korean dental hygiene students.

A moderately close relationship between HU-DBI and ORI for dental hygiene students as a whole supports the view that the Korean version was an appropriate behavioral test for gingival self-care levels. Although there was no significant relationship in year-3 students, the sign of the coefficient for the association in each level of education was the same as that expected. The ORI uses a set of standard color photographs of each level of the scale to maintain consistent standards. It is undertaken without hand 
instruments under natural light. The ORI is not a strict quantitative index for the determination of oral health status, and clinical assessment and screening by ORI does not specifically diagnose periodontal disease (14). However it seems to provide a good indicator of a person's commitment to gingival self-care among Koreans.

Some limitations of this study are evident. First, any changes in HU-DBI scores and ORI scores cannot unequivocally be attributed to the curriculum, since these data were cross-sectional. They must be validated by longitudinal studies. Second, the school environments in this study may not be representative of other Korean dental hygiene schools for factors such as educational setting, training program and geographic origin. By 1994, dental hygienists were being trained in junior technical colleges offering a 2-year course and in three attached dental clinics of three colleges of dentistry with a 3-year course for dental hygienists. The school in this study is one of the two private schools in the south-west of Cholla Province. In 1994, all 2-year dental hygiene programs were extended to 3-year courses. Today, oral health education is taught in all 24 dental hygiene programs and is practiced in a laboratory setting. Although caution should be exercised in generalizing the results of this study, the variation in the favorable attitudes/behavior toward oral health and improvement of gingival self-care level appeared to reflect the students' clinical training experience.

\section{Acknowledgments}

The authors are grateful to Mr Sik-Jong Ha at Hiroshima University of Economics (former), for translating the HUDBI questionnaire into Korean, and Ms Sookja Suh, for her assistance with this study. This paper was supported in part by Wonkwang University 2000.

\section{References}

1. Moon, H-S., Jung, J-Y., Horowitz, A.M., Ma, D-S. and Paik, D-I. (1998) Korean dental hygienists' knowledge and opinions about etiology and prevention of dental caries. Community Dent. Oral Epidemiol. 26, 296-302

2. Frazier, P.J. (1985) Public health education and promotion for caries prevention. The role of dental hygiene programs. Dent. Hyg. Chic. 59, 210-217

3. Uitenbroek, D.G., Schaub, R.M.H., Tromp, J.A.H. and Kant, J.H. (1989) Dental hygienists' influence on the patients' knowledge, motivation, self-care, and perception of change. Community Dent. Oral Epidemiol. 17, 87-90

4. McConaughy, F.L., Lukken, K.M. and Toevs, S.E.
(1991) Health promotion behaviors of private practice dental hygienists. J. Dent. Hyg. 65, 222-230

5. Brown, L.F. (1996) A comparison of patients attending general dental practices employing or not employing dental hygienists. Aust. Dent. J. 41, 4752

6. Abraham, N.J., Cirincione, U.K. and Glass, R.T. (1990) Dentists' and dental hygienists' attitudes toward toothbrush replacement and maintenance. Clin. Prev. Dent. 12, 28-33

7. Kawamura, M., Ikeda-Nakaoka, Y. and Sasahara, H. (2000) An assessment of oral self-care level among Japanese dental hygiene students and general nursing students using the Hiroshima University-Dental Behavioural Inventory (HU-DBI): Surveys in 1990/1999. Eur. J. Dent. Educ. 4, 82-88

8. Andersen, R., Marcus, M. and Mahshigan, M. (1995) A comparative systems perspective on oral health promotion and disease prevention. In Disease prevention and oral health promotion. Cohen, L.K. and Gift, H.C., eds., Munksgaard, Copenhagen, 307-340

9. Kawamura, M. (1988) Dental behavioral science. The relationship between perceptions of oral health and oral status in adults. Hiroshima Daigaku Shigaku Zasshi 20, 273-286 (in Japanese)

10. Kawamura, M., Aoyama, H., Sasahara, H., Tsuchida, K., Nagao, M. and Iwamoto, Y. (1988) Behavioral dental science. Part VIII. The dentist's rating and adolescents' perceptions of oral health. Nippon Shishubyo Gakkai Kaishi 30, 1097-1107 (in Japanese)

11. Kawamura, M., Kawabata, K., Sasahara, H., Fukuda, S. and Iwamoto, Y. (1992) Dental behavioral science. Part IX. Bilinguals' responses to the dental behavioral inventory (HU-DBI) written in English and in Japanese. Hiroshima Daigaku Shigaku Zasshi 24, 185-191 (in Japanese)

12. Kawamura, M., Iwamoto, Y. and Wright, F.A.C. (1997) A comparison of self-reported dental health attitudes and behavior between selected Japanese and Australian students. J. Dent. Educ. 61, 354-360

13. Frazier, P.J. (1992) Research on oral health education and promotion and social epidemiology. J. Public Health Dent. 52, 18-22

14. Kawamura, M., Fukuda, S., Inoue, C., Sasahara, H. and Iwamoto, Y. (2000) The validity and reproducibility of an oral rating index as a measurement of gingival health care and oral hygiene level in adults. J. Clin. Periodontol. 27, 411-416 